\title{
ERRATUM
}

H. Fjeldsøe-Nielsen • M. Unemo • H. Fredlund •

S. V. Hjorth • L. M. Berthelsen - H. M. Palmer .

A. Friis-Møller

\section{Phenotypic and genotypic characterization of prolyliminopeptidase-negative Neisseria gonorrhoeae isolates in Denmark}

Published online: 21 June 2005

(C) Springer-Verlag 2005

\section{Eur J Clin Microbiol Infect Dis (2005) 24:280-283}

Figure $1 \mathrm{~b}$ was omitted from the print version. The complete figure is given here.

The online version of the original article can be found at http://dx.doi.org/10.1007/s10096-005-1319-5

H. Fjeldsøe-Nielsen · A. Friis-Møller $(\bowtie)$

Department of Clinical Microbiology, H:S Hvidovre Hospital, Kettegaard allé 30,

2650 Hvidovre, Denmark

e-mail: alice.friis-moeller@hh.hosp.dk

Tel.: +45-36322411

Fax: +45-36323357

M. Unemo $\cdot$ H. Fredlund

Swedish Neisseria gonorrhoeae Reference Laboratory,

Department of Clinical Microbiology, Örebro University

Hospital,

70185 Örebro, Sweden

S. V. Hjorth · L. M. Berthelsen

Danish Neisseria gonorrhoeae Reference Laboratory,

Department of Bacteriology, Mycology and Parasitology,

Statens Serum Institut,

Artillerivej 5,

2300 Copenhagen S, Denmark

H. M. Palmer

Scottish Neisseria gonorrhoeae Reference Laboratory,

Department of Clinical Microbiology, Royal Infirmary of

Edinburgh,

Little France, Edinburgh, EH16 4SA Scotland, UK

\section{a} Distinguishable Spel
fingerprints

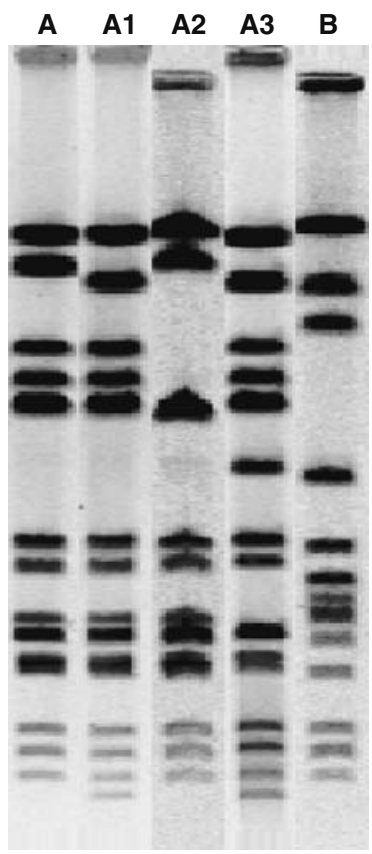

Fig. 1a, b One representative of each distinguishable PFGE-fingerprint, using SpeI $(n=5)$ and $B g l I I(n=4)$, of prolyliminopeptidase (PIP)-negative isolates of $N$. gonorrhoeae collected in Denmark $(2002-2003, n=26)$ and the UK $(2000-2002, n=3)$ b Distinguishable BgllI

$\begin{array}{llll}\text { a } & \text { a1 } & \text { a2 } & \text { b }\end{array}$

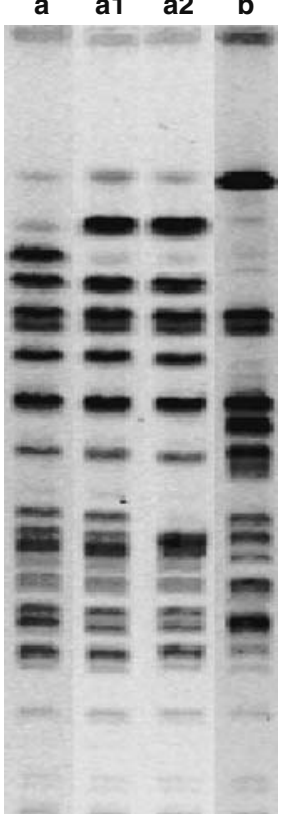

